\title{
Internet of Things Promoting Learning Theory Based on "Complex Information Holographic Person "Perspective
}

\author{
Tianbo Zhang \\ Guangdong Industry Technical College \\ Guangdong,Guangzhou, 510300, China \\ e-mail:1985101083@gditc.edu.cn
}

\begin{abstract}
Based on the complementary principle of quantum mechanics and quantum of " information complexity holographic person "(QICHP) hypothesis that the learning process is a "giant complex adaptive intelligent systems", in which there is information exchange, storage and handling of the process, the final nature of the learning is to create a happy life. Internet of things could complete the interconnection between T2T(Thing to Thing), H2T(Human to Thing), H2H(Human to Human), H2S(Human to Shi), T2S(Thing to Shi) and S2S (Shi to Shi). The Internet of things could also complete the Digital (virtual) of the material world, data processing intelligent, learning object personified. Learning theory and human nature assumption was compatible, biological people assumption, rational people assumption, social people hypothesis, self-realization people hypothesis and information people assumption are respectively corresponding to behaviorism, cognitivism, constructivism, humanistic, the distributed cognitive learning theory. At the information age Internet of Things will be widely used, the "QICHP" will correspond to "quantum information ecological learning theory".
\end{abstract}

Keywords- complex quantum information holographic people; Internet of Things; littoscopic learning; quantum information ecological learning theory ; ubiquitous subject

\section{INTRODUCTION}

From ancient times to now, research learning is one of the important human social practice, the human's own understanding is deepening. For definition and nature of learning, there was also different understanding, and was formed the corresponding learning theory. For the widespread application of Information technology, cloning technology and IoT, person's own information, complexity, holographic, quantum features are particularly important. Based on the theory of complex systems and the complementary principle, this article proposed quantum hypothesis of " information complexity holography people "(ICHP), ${ }^{[1] a}$ nd to think about learning theory. Based on impact analysis of IoT to education and learning, the article had proposed learning theory of quantum information age-"quantum information ecology learning theory".

\section{CHANGES IN HUMANITY ASSUMPTION AND LEARNING THEORY}

Some scholars have analyzed nearly 30 years of domestic learning theory, there are constructivism, behaviorism, cognitivism, humanism learning theory, the theory of independent learning and situated learning theory ${ }^{[2]}$ With the scientific and technological progress and economic and social development, different learning theory respectively corresponding to different assumptions of human nature. Following five humanity assumption and corresponding learning theory are as examples. Based on biological people hypothesis, the "behavioral learning theory" was produced, under certain conditions of time and space, due to the conditioned stimulus and the unconditioned stimulus It claims that learning is an organism combined to form a contact for a new experience in the process, the learning body is passive stimulation. "rational people assumption" Led to "cognitive learning theory ", It claims that learning is a process of the learners formation or development of cognitive structure by on proactive internal cognitive operating activities, learning the main body is actively stimulated. $^{[3]}$

Associated with the constructivist learning theory is "social man" hypothesis of human nature, constructivism firmly believe that knowledge is the result of active construction by the cognitive subject, learning is a cognitive subject meaning construction process. The learning main body is self-knowledge construction. Consistent with humanistic learning theory is the assumption of Maslow's "self-realization human". its view is that the main body of learning is student, learning is both an emotional and cognitive unity of spiritual activities, and it's valuable to the individual learn, meaningful learning. Professor $\mathrm{Yu}$ Shengquan studied in detail the distributed cognitive learning theory, and proposed the establishment of "educational information ecosystem", that is, information human, education practice and technology environment constitutes a self-organizing, self-evolution of the system, its maximum system value is to promote the comprehensive development of teachers and students. ${ }^{[4]}$ It can be considered the distributed cognitive learning theory corresponding to the assumptions of the "information man". Learning theory compatible with the "information man" hypothesis is also situated cognition theory and social cognitive theory and network learning theory.

\section{III. "QUANTUM INFORMATION COMPLEXITY HOLOGRAPHIC PERSON "ASSUMPTION}

The object of the research is about people's learning, to learn is to happiness in life, to reflect the joy in learning, therefore, people are learning the starting and ending points. 
I have proposed: the people must be seen as one of tens of trillions of sub-systems and small systems, large systems with dissipative structural, informational, holographic, with self-awareness and adaptive quantization, the nature of the open complex giant system -- giant complex adaptive intelligent systems (Giant Complexity Adaptive Intelligent System, abbreviated as GCAIS, referred to as: 格赛思), referred to as "information complexity holographic person". ${ }^{[5]}$ Where human participation in the activities of the system are the giant complex adaptive intelligent systems. The learning system is a system composed of subject, object, media and environment, so learning is "格赛思"(GCAIS). Learning system in addition to the open complex giant system openness and heterogeneity of the components, the structure of the hierarchy, the dynamic nature of the behavior and the overall emergent property characteristics, it also has information, quantum, holographic. Learning to get more and better information, The nature of learning is to increase the information entropy of subject, Learning's information is not self-evident.

Learning quantum mainly embodied by quantum. one can see the objective object because the visual cells receiving the information of quantum fluctuations, visual awareness, and visual image of the object in the network of nerve cells. The propagation velocity is less than the vacuum speed of light in air, water and glass in the quantum substance interaction slowed down, similarly, the light through the pupil and the melt will slow down, light quantum has "Wave-particle duality", any interaction with light can be considered to be quantized. I have put forward that consciousness generated "volatility, particle, information, awareness, the four images " of nerve cells (Abbreviation: wave-particle- information- awareness four images). [6] Memory is brain thinking cells 's "Cork prominent" or "Cork prominent fractal " Limited brain capacity can accommodate unlimited "Cork prominent ", thus the brain there is an infinite memory. The learning's microscopic nature is from "wave-particle- information- awareness four images". Learning quantum performance was learning content (objects) is quantized (expression) through the quantization; The learning process is quantized; The learning media information is quantized and so on .in other words, the expression of learning information must be quantized, only quantized presented to quantum human sensory organs received.

The human hereditary showed that a gene cells is holographic, the cloning technique illustrated holographic characteristics, a person is a "elements of the universe the holographic point",a school is modern national education system "elements holographic point ", the activities of person's learning is an "elements holographic point" of "doing things ".

\section{INTERNET OF THINGS IMPACTING TO LEARNING}

\section{A. The Concept of IoT}

Internet of things links them to which can not move "things" or not self-expression "things", by means of RFID technology, intelligent embedded technology, sensor technology and other advanced devices and techniques, and to make a real integration of the entire human world. This paper argues that: IoT is a giant complex adaptive intelligent system, some kind systems (people, objects, events, information) - Network - the Internet - a network tool for servicing human well-being.

The philosophical nature of IoT can be considered a virtual entity, digital, information, communicating the real world and virtual world by means of information, forming a self-organizing capacity of the independent network. Virtual entity of IoT garble physical objects, animals, people, robots, things (pieces) and other concepts, causing material and spiritual blurred the boundaries of dualism.

\section{B. Functionality of IoT}

In addition to these features, such as "the physical world digital (virtual) technology ", " people, objects, things (pieces of) the Internet-based", " education resources information ",and " data processing is intelligent", the Internet of things also has the following aspects of function, Fifth, learning object personified, the implication is that the learning object to the learners take the initiative to issue their own knowledge and information through voice, images or other symbols, each learner is immersed into the real world into the virtual world and the digital world intertwined information ecological environment. Sixth, the education system counseling, school weakening as the counseling agencies. Seventh, student counseling of individual growth and development. be educated became Real learning subject, educational Evolution learners individual learning and growth, can be referred to as "student counseling", this is most fundamental impact to the education of the IoT. Eighth, the miniaturization of teaching time and space, global village and distance education teaching space smaller teaching time, body in the country can be timely and easily learn a foreign university open courseware or video.

\section{I oT Affecting "Teaching "}

It was suggested that the concept of " ubiquitous education" where can enhance individual fitness in the form of social ability to pass information exchanges absorption can be summarized in the " ubiquitous education" category, [6] Similarly, who can increase the main useful amount of information or information entropy activities can be considered to be "learning", " ubiquitous learning ". It's not only the ever-present, nowhere, and but not specific subject, you can say "ubiquitous subject" for "ubiquitous learning " The essence of teaching is a kind of "doing work," the practical activities. "Objects have physical ", someone has his reason ","thing is its affair", "to do work " is with the truth of "doing work". ${ }^{\text {[7] }}$ 
Now the "teaching", which means "teaching" the main "teaching" the teacher's initiative "teaching" learning, "learning" of students is in a secondary position. The Internet of Things and people-oriented era, the breadth of teaching and learning can be called " ubiquitous teaching" and "ubiquitous learning", that is, everywhere in the "teaching" and the ubiquitous "learning." The teacher's "teaching" teaching to achieve ubiquitous and well-being of the religion .All the work of teachers for students to take the initiative of the "learning" services, Teachers to "teach" How effective is reflected in the student counseling, guidance, guide", Teaching" becomes a "learning guidance", therefore, the teaching paradigm has changed.

\section{IoT Affecting "Learning"}

IoT era of cloud computing, the sea and the clouds calculated to adapt the calculation of "cloud services" for the people of knowledge and information is no longer subject to space, time, physical, knowledge, information restrictions and other differences, can demand access, share knowledge and information."Learning" into a truly "independent learning". IoT to make learning the way, means, time, content, and will be a fundamental change, evaluation of the effectiveness of learning methods and tools will change accordingly.

\section{QUANTUM INFORMATION ECOLOGICAL LEARNING THEORY}

\section{A. The Definition and Classification of Learning}

The learning process is a process of individual practice (work) activities, the nature of learning is of the individual in the process of "doing things" to acquire new knowledge, new skills and develop good quality information processing activities. The learning system is the "GCAIS ". According to the study of the spatial and temporal scales, and to participate in the main ubiquitous, the learning can be divided into littoscopic learning, microscopic learning, macroscopic learning, cosmoscopic learning and bulgoscopic learning five levels.

"Littoscopic learning " refers to the individual learning primitive cells can be called "learning atom ",its potential has not been felt, but already exists in the individual subconscious (preconscious),as if to constitute the material elements of the atom or electronic state, not yet shown the molecular properties of the substance. Learning structure and hierarchy can be different "learning atom", such as carbon atoms may form structure which is different from diamond, can also be of graphite. the Learning atom the different structure of will form a distinct "learning elements", to show different results or function. Different structure " Littoscopic learning" essentially different nerve cells or networks caused "Cork Shaping".

"Microscopic learning" refers to a collection of individuals or superficial of "littoscopic learning ", Both if subconscious rise to the conscious, if atom or a combination of the electron state and the formation of molecules that can be referred to as a "learning molecules "."Microscopic learning" can show different qualities of learning, such as rote, to observe the scene, hands and other different learning paradigms, reflected in the learning process or the way their brains main, or experience, or hands-main.

"Macro-learning" refers to groups (groups or groups) of learning, as well as the activities of individual learning space, longer duration of learning, usually refers to the current school education or enterprises and training. Macro-learning is also research the most, almost all of the learning theory is about macro learning.

"Macrocosm learning" means learning subjects (containing observe the main appreciation of the main activities in the main, etc.) more and a greater range of practical activities, such as large gatherings, performances or individual non-directional experience activities, but also refers to the usual sense of the generalized learning or the ubiquitous learning. "

The "bulgoscopic learning" refers to a wider range or cross-border activities of practice, mankind universal learning. The overall purpose of the pursuit of peace and stability of the human, is sustainable survival and development of mankind, such as cross-border or crosslanguage community learning, relevant United Nations organizations learning.

The "littoscopic learning" is learning elements (atoms), "microscopic learning" is learning primitives (molecule or unit), the "macroscopic learning" is learning the subject, the Macrocosm learning is supplementary learning, the bulgoscopic learning "is the ultimate goal of human learning.

\section{B. The Definition of Quantum Information Ecological Learning Theory}

One of the teachers "teach" happiness and students happy "study" should become the subject of modern education technology research. In this paper, the so-called "quantum information ecology learning theory called quantum information ecology learning paradigm". It is the main learning is quantized, in the context of the people of holographic comprehensive practical activities to achieve the psychosomatic pleasure and purpose of continuing happiness in life activities. Learning is "doing things", learning is the life, learning to be happy and want to experience the happiness of life.

\section{The characteristics of Quantum Information Ecological Learning Theory}

Here defined quantum information ecology learning theory have many characteristics such as information quantization, real-time holographic, distribution integration, personality contextualised, the ubiquitous learning and so on.

"Quantum information" refers to the performance of learning information is quantized. All of the feeling of the person there is a minimum unit, like a light quantum, language word, sound of threshold. Information receiving, processing, and expression should also be quantized. 
"Real-time holographic" refers to the learning process and the results are real-time holographic. Practical activities of the people by the quantum form of time holographic lead to information particles. the learning's results of the structure of matter can be genetic, structure determines function, the structure genetic lead to the corresponding function genetic, that human ingenuity can be genetic.

"Distribution integration" refers to the cognitive learning is integrated distribution. Cognition is uneven distribution not only in the mind, but also distribution in all sensory systems or expression system, or other central nervous system. Hutchins think that the nature of cognition is "distributed" ,cognition is distributed in the individual, individuals, the media, the environment, culture, society and time being. Such as cognition is distribution in time. Cognition lateral distribution in the a unique time dimension of the each cognition body, vertical distribution in specific cognition subject in the past, present and future. Such as Cognition is intraindividual distribution. Knowledge in the brain is non-uniform distribution. Cognition science and cognition neuroscience modules doctrine to support this view.

A man is a "quantum information complexity holographic person "(QICHP), objective world contact channel is multifaceted, information exchange, transfer, storage and expression is non-symmetric and non-uniform. Eyes, ears, tongue body is the main channel of information. The knowledge and skills of people are not all uniform being stored in the brain, perhaps the different channels of information exchange or organ has a possible temporary storage of knowledge or skills. Stem cells throughout the body are likely to be a cognitive storage, they can play a different role about cognition. Wrong phenomenon often occur in interpersonal communication. There may be visual organ originally stored in a shape similar information interference, looked at the man, but the mind has emerged out of the image of another person. People in speech or speech appears slip of the tongue, it may be sound organ control system automatically tune out the original cognitive information. When writing, clerical error appears, which also may be a control the write instruction issuing original cognitive or memory. Conditioned reflex in the usual sense, can be understood as a reaction to extern al stimuli, a local cognitive.

"Situational personification" may be referred to as "learning in the field of complementary principle", which is the context people being influenced by the observer, it is determined by the complementary principle of quantum mechanics. It expresses philosophical implication on the interaction of the experimental apparatus being observed and the object. Different individuals have different learning effects in the same context; the same individual in the same scenario but different time, there are different feelings that is to say, the scenario by the individual is feeling, or feeling (feeling) of the individual situation influenced by individual factors. Cognition is the information processing process of the individual level. That is to say, of the microscopic fields, which can also be understood as the higher order infinitesimal calculus can not be ignored from the perspective of mathematical analysis.

"Learning the ubiquitous" refers to learning objects, learning styles, learning content and learning subjects are the ubiquitous. Mortal beings, who need learn, must learn. In the information world, all people are actively or passively receive information. The main body unwilling to accept the interference of the information, but have to accept, then it become the Information alienation. Of learning field, it is called as "learning alienation ".Children's reverse psychology is one of the manifestations of alienation.

\section{CONCLUSIONS}

"QICHP" is designer, implementer, and participant in the learning activities, its own information, quantum complexity, holographic makes "learning theory" presents as a complex diversity. Widely used in the information age of today's advances in technology, the IoT has produced a profound change in human learning and lifestyle. It must also have a learning theory, as an attempt this article put forward "quantum information ecological learning theory".

\section{ACKNOWLEDGMENT}

This work was supported by Ms. Li Qiuhong, and by Guangdong Province Education Science "12th Five-Year" Plan (No.:2012JK091), the Guangdong Higher Education Projects (No.:GJB125095).

[Author] Tianbo Zhang (1957-), male, Bozhou in Anhui, associate professor, corporate law consultant. mainly engaged in teaching, vocational education, management.

\section{REFERENCES}

[1] Tianbo ZHANG, Liliang ZHANG. Public welfare of humanity under the framework of the assumption that occupational education[J]. Modern Enterprise Education, 2011, 391 (10) : 50-52.

[2] Zeng WenJie, Xu Sumei. Thirty years of learning theory research [J]. Educational Technology Research, 2012, (10) :34-40 .

[3] Qu Linyan. Learning theory and learning innovation [J]. Higher Education Research, 2008,29 (01) :70-78.

[4] Yu Shengquan, Chen Li. Construct a harmonious information ecology and break through the plight of education information [J] Distance Education of China, 2006, (5): 19 to 24

[5] Tianbo Zhang. Based on the assumption of human nature "things" structural analysis [J]. Education Teaching Forum, 2012, (39) :117.

[6] Tianbo ZHANG. Analysis on the structure and level of modernnational education system from the lifelong education dimension[J].Vocational and Technical Education, 2011, 32 (22) : 31-35.

[7] Tianbo Zhang Lifelong education system, vocational education positioning thinking [J]. Guangzhou: Guangdong Technical Teachers College (Vocational Education), 2012, (01) :11-14. 